\title{
Vulnerability and Risk Assessment of a State University in the Philippines
}

\author{
Marc Alexei Caesar B. Badajos \\ Central Philippines State University, Kabankalan City, Philippines \\ macbadajos78@gmail.com \\ https://orcid.org/0000-0001-8526-8361 \\ Merlita V. Caelian \\ University of Negros Occidental-Recoletos, Bacolod City, Philippines \\ merlita_caelian@yahoo.com
}

\begin{abstract}
This descriptive-comparative research determined the vulnerability and risk, including the adaptive capacity of the university exposed elements: population, natural resources, and facilities. A researcher-made survey questionnaire was used to determine the adaptive capacity of these elements. It was administered to 598 randomly selected respondents composed of students, faculty, and non-teaching personnel from the three campuses. An assessment survey was also conducted over three groups of purposively selected students, personnel, and external stakeholders for vulnerability and risk. Using the descriptive and inferential analyses, the study yielded a high adaptive capacity for all exposed elements and a significant difference when respondents were grouped into campuses. Likewise, all campuses have a very low vulnerability and a low risk to a landslide but have a different risk to flooding: B has a high risk, $A$ is moderate, while $C$ has no risk. Findings suggest that each campus has to be treated differently to address priority areas.
\end{abstract}

Keywords: Climate Change, Adaptive Capacity, Vulnerability and Risk Assessment, State University, Negros Occidental, Philippines

Date Submitted: September 27, 2019

Date Revised: December 5, 2019

Date Accepted: December 29, 2019

\subsection{Introduction}

Climate change sits on top of the priority regarding the global issue on the environment (Intergovernmental Panel on Climate Change [IPCC], 2012). Thus, the Sendai Framework for Disaster Risk Reduction 2015-2030 identifies disaster risk as a 
priority, emphasizing all its dimensions: vulnerability, adaptive capacity, exposure, hazard characteristics, and the environment as the bases for formulation of policies and practices for its management. This framework also identifies the roles of government institutions and the different stakeholders, including the academe (UN/ISDR, 2015).

Despite government efforts, the Philippines still ranked as one of the top ten most affected countries in the world regarding the Long-Term Climate Risk Index from 1997-2016 based on the German Watch report in 2016 and 2017 (Eckstein, Künzel, \& Schäfer, 2018). The high level of risk was attributed to the geographic location. Because the Philippines is in the ring of fire and lies in the Pacific, thus, it is vulnerable to disasters. The lack of coping and weak adaptive capacity further aggravated the risk (Institute for International Law of Peace and Armed Conflict, 2018).

Several studies which link adaptive capacity to education have been conducted such as those of Wamsler, Brink, and Rantala (2012); Ardales, Espaldon, Lasco, Quimbo, and Zamora (2017); Alcayna, Bollettino, Dy, and Vinck (2016) and Matyas and Pelling (2015). Abdul-Razak and Kruse (2017) focused on smallholder farmers of Ghana. Gomez (2013) studied the impact of climate change on agriculture. Furthermore, related studies on disaster management have been conducted in Negros Occidental which focused on the three phases of disaster (Mabag, 2015); awareness and disaster resiliency of local government units (Caelian, 2015); awareness and implementation of Disaster Risk Reduction and Management practices in private education institutions (Papa, 2019). However, no study on vulnerability and risk of state universities has been conducted in Negros Occidental; hence, a gap in the literature.

A University is where students, personnel, and other stakeholders converged for long periods. Some campuses have developed into a community with permanent residents. Thus, the University is responsible for ensuring the safety of these people, including its natural resources and facilities. However, the inadequate resources of the University cannot simultaneously address the needs of all campuses, thus shall prioritize those prone to disasters as effects of climate change. Findings on vulnerability and risks of each campus, including its adaptive capacity, will serve as a basis of a participatory, scientific approach to come up with specific solutions to mitigate disasters and the effects of climate change at less cost and in an appropriate time frame.

This study assessed the vulnerability focused on the levels of adaptive capacity of the population, natural resources, and critical facilities of the University as assessed by the students, faculty, and non-teaching staff when they are taken as a whole and when grouped according to campus. Likewise, it determined the vulnerability in terms of climate stimuli categorized into an increase in temperature and an increase in rainfall. It investigated as well the level of risk to flooding and landslides. It also looked into the challenges encountered by University campuses to respond to climate change and disaster risks. The study likewise sought to determine if there are significant differences in the level of adaptive capacity of the exposed elements of a state university when they are grouped according to campus. A proposed program for enhanced adaptation and mitigation to climate change and disaster risks of university campuses was formulated. 


\subsection{Framework of the Study}

The Vulnerability Assessment Framework developed by Turner et al. (2003) introduced an assessment for a coupled human-environment system which identified the elements to be included in any vulnerability analysis such as multiple interacting stresses and their sequencing, exposure and the manner the systems experiences hazards, sensitivity of the system to the exposure, the system's capacity to cope or respond, the risks of recovery, adaptive capacity of the system, and the dynamics of interaction of hazards, sensitivity and adaptive capacity of the system. Anextensive approach to the human-environment system was the Socio-Ecological Systems (SES) theory by Ostrom (2009). The framework espoused that an organization is affected by its external environment and the broader human and biophysical (environmental) conditions and processes operating within the system.

According to Ciurean, Schroter, and Glade (2013) and Cumming (2014), the vulnerability framework is categorized as an assessment-oriented framework for socialecological systems which is consist of a time and location-specific, coupled humanenvironment system with a distinctive features and levels of exposure, sensitivity, and coping capacity; perturbations and disturbances affecting the local system; complexity and interactions involved in the vulnerability analysis; and interactions with the broader social, and environmental background.

The study is anchored on this theory that vulnerability is a function of adaptive capacity, exposure, and sensitivity of the exposed elements of the university and is affected by both the internal and external environment. The external environment represents the community, the local government, and the various sectors that can influence the University system, while the internal environment represents the conditions within the University system, which are both social and biophysical. The level of risk is presented as a function of the severity of consequence and likelihood of occurrence of a particular hazard. The risk may be occurring within the system or outside the system, but due to their interconnectivity, it still affects and influences the University system.

The framework is embodied in the study because it makes use of the place specific analysis of the effect of the hazards on the University system arising from influences outside and inside the system and place, although their precise character is commonly specific to the location. It also emphasizes the presence of feedback between the social and biophysical subsystem where one's coping action make the other less vulnerable and vice versa. The findings on the contribution of these variables, together with the challenges encountered by a state university, formed the basis of an enhanced program on adaptation and mitigation measures to cope with climate change and disasters.

\subsection{Methods}

This study used a descriptive-comparative research design. The descriptive approach was used to measure a large mass of respondents (Ritchie, Lewis, Nicholls, \& Ormston, 2013) students, faculty, and non-teaching staff and determined the adaptive capacity of the exposed elements. The comparative approach allowed the researcher to examine the differences and similarities (Spata, 2003) in the level of adaptive capacities when the respondents were grouped according to campuses. 
The researcher-made survey instrument consists of three parts. Part 1 is the respondents' profile. Part II are questions to determine the adaptive capacity of the exposed elements, and Part III asks of the challenges encountered by campuses in responding to climate change and disasters. The questionnaire was subjected to a validity test using the criteria of Good and Scates with five jurors. The validity score is 4.43, which means that the instruments are valid. Reliability was tested using the Cronbach Alpha Method administered to 30 students and faculty who did not participate in the actual data gathering. The alpha coefficient is 0.940 , which ensured the instruments' reliability. A total of 598 respondents distributed to the different campuses were selected using stratified random sampling with proportional allocation. The actual respondents in each campus were randomly selected from the list of students, faculty, and non-teaching personnel. The data gathering process supported the study of AbdulRazak and Kruse (2017), where a survey questionnaire was used to solicit primary data of the adaptive capacity.

Furthermore, an assessment survey that determined the vulnerability and risks was conducted on three groups of respondents selected based on prescribed criteria. The first two groups were composed of students and personnel of the campus selected based on the following: a member of their respective council, enrolled for more than a year, and at least 3-years employed for personnel. The third group was specifically selected based on their background on planning and DRRM activities either as personnel of the University or from the LGU.

The assessment survey followed a step by step process based on HLURB guidelines. Vulnerability index is a quotient of the degree of impact score and adaptive capacity. Adaptive capacity was measured using the scales of 1 very low, 2 low, 3 moderate, 4 high, and 5 very high. Risk Index was determined as a product of the severity of consequences score between 1 (low) to 4 (very high) and the likelihood of occurrence score between 1 (very rare) to 6 (frequent).

Before the assessment survey, the researcher obtained the permission of the campus administrators and local chief executives of concerned LGU by explaining the purpose of the study. The same information was provided to all respondents to get their informed consent. They were assured of the anonymity, and the confidentiality of the information gathered. They were informed that they could withdraw participation anytime if they feel uncomfortable in the data gathering. The raw materials gathered were shredded as soon as the results were encoded.

\subsection{Results and Discussion}

\section{Level of Adaptive Capacity of the Exposed Elements of the University}

The level of adaptive capacity of the university campuses as a whole is high. All systems of interest had a "high" rating, with population rated the highest $(\mathrm{M}=3.63)$ followed by natural resources $(M=3.56)$ and critical facilities $(M=3.46)$ the lowest. These figures mean that campuses can cope and manage the effects of climate change and disasters. This high level of adaptive capacity is attributed to the availability of human, physical, and financial resources. The findings are supported by Epstein et al. (2014), 
Alcayna et al. (2016), Abdul-Razak and Kruze (2017) and Ardales, et al. (2017), who all identified financial capacity as key to the overall adaptive capacity of an institution.

In the area of population, both Campus B and $C$ had a high adaptive capacity, while Campus $A$ revealed a moderate rating. The high adaptive capacity of the population reflects the awareness of students and school administrators of climate change and disasters as supported by the study of Papa (2019), which also revealed higher awareness of students and administrators of public secondary schools and private education institutions in Negros Occidental, respectively. The study of Acosta et al. (2016) also supported this finding that high adaptive capacity is attributed to the respondents being highly educated and knowledgeable of previous disasters. Reams, Lam, Cale, and Hinton (2013) affirmed that environmental education programs deliver information about hazards within the community, including threat levels. Thus, the adaptive capacities of the residents living within the campuses of the University are enhanced, consistent with the socio-ecological systems theory.

The adaptive capacity of university campuses in the area of natural resources as a whole is high and is attributed to the fact that the flagship program of these campuses is agriculture. Hence, the University was able to enhance its adaptive capacity, supporting the study of Abdul-Razak and Kruze (2017) that those with formal education have higher adaptive capacity compared to farmers without formal education. Another factor that contributed to the high adaptive capacity of university campuses on natural resources is its agricultural extension services and also the linkage and support of local and national agriculture office. The findings are in harmony with those of Gomez (2013) that social networks contribute to the invulnerability of farmers to climate change.

Adaptive capacity as rated by students, faculty and non-teaching personnel as a whole was high, with the highest rating from students and the lowest rating from the faculty. Both students and non-teaching staff gave a high rating for all systems of interest, while the faculty has a high rating for the population $(M=3.52)$ and moderate rating for critical facilities $(M=3.35)$ and natural resources $(M=3.37)$. These ratings are attributed to the faculty's familiarity and knowledge of this system of interest. Most faculty respondents have been with the University for more than five years, and they are using the facilities regularly as compared to the student.

In determining the adaptive capacity of facilities, assessment validation was also conducted. This procedure is consistent with the study of Fakhruddin, Babel, and Kawasaki (2015), where stakeholders determined the degree of the capacity to repair the facilities of the University campuses. This study recognized the value of the stakeholders who are the experts as they presented a different view of the status of the infrastructures and being the best available source to estimate the capacity of repair of the non-physical damage to infrastructure.

The adaptive capacity of the University campuses in the area of facilities as a whole is moderate $(M=3.46)$. Campus $C$ got the highest $(M=3.61)$, while campus $A$ was rated the lowest $(M=2.91)$, although interpreted as moderate. Campus $B$ was also rated moderate $(M=3.45)$.

These findings validated the results of the validation assessment and observations that the facilities of government schools/institutions cater to students 
beyond their carrying capacity hence a lower adaptive capacity. This finding corroborates that of Antwi (2015) that among others, physical, or engineering indicator is expected to impact a community either directly or indirectly to produce a specific outcome such as the lower adaptive capacity to disaster and climate change.

Ciurean, Schröter, and Glade (2015) emphasized that for the facilities, the short-term effects of disaster and climate change include structural damages, interruption of services, or direct economic losses. Also, the long-term effects include indirect economic losses, social disturbance, and environmental degradation.

Table 1. Level of Adaptive Capacity of the Exposed Elements

\begin{tabular}{|c|c|c|c|c|c|c|c|c|c|c|c|c|}
\hline \multirow[t]{2}{*}{ Variable } & \multicolumn{3}{|c|}{ Population } & \multicolumn{3}{|c|}{$\begin{array}{l}\text { Natural } \\
\text { Resources }\end{array}$} & \multicolumn{3}{|c|}{ Critical Facilities } & \multicolumn{3}{|c|}{ As a Whole } \\
\hline & $M$ & SD & Int & $\mathrm{M}$ & SD & Int & $\mathrm{M}$ & SD & Int & $\mathrm{M}$ & SD & Int \\
\hline \multicolumn{13}{|l|}{ Respondent } \\
\hline Student & 3.67 & 0.70 & $\mathrm{H}$ & 3.59 & 0.77 & $\mathrm{H}$ & 3.50 & 0.82 & $\mathrm{H}$ & 3.60 & 0.73 & $\mathrm{H}$ \\
\hline Faculty & 3.52 & 0.74 & $\mathrm{H}$ & 3.37 & 0.75 & $\mathrm{M}$ & 3.35 & 0.81 & $\mathrm{M}$ & 3.43 & 0.69 & $\mathrm{H}$ \\
\hline NTP & 3.58 & 0.64 & $\mathrm{H}$ & 3.55 & 0.69 & $\mathrm{H}$ & 3.42 & 0.71 & $\mathrm{H}$ & 3.53 & 0.62 & $\mathrm{H}$ \\
\hline \multirow[t]{2}{*}{ Variable } & \multicolumn{3}{|c|}{ Population } & \multicolumn{3}{|c|}{$\begin{array}{l}\text { Natural } \\
\text { Resources }\end{array}$} & \multicolumn{3}{|c|}{ Critical Facilities } & \multicolumn{3}{|c|}{ As a Whole } \\
\hline & $M$ & SD & Int & $\mathrm{M}$ & & $\mathrm{M}$ & SD & Int & $\mathrm{M}$ & & $\mathrm{M}$ & SD \\
\hline \multicolumn{13}{|l|}{ Campus } \\
\hline A & 3.13 & 0.67 & $M$ & 3.08 & 0.68 & $M$ & 2.91 & 0.83 & $\mathrm{M}$ & 3.02 & 0.67 & $M$ \\
\hline B & 3.66 & 0.62 & $\mathrm{H}$ & 3.50 & 0.71 & $\mathrm{H}$ & 3.45 & 0.71 & $\mathrm{M}$ & 3.55 & 0.63 & $\mathrm{H}$ \\
\hline $\mathrm{C}$ & 3.74 & 0.69 & $\mathrm{H}$ & 3.68 & 0.76 & $\mathrm{H}$ & 3.61 & 0.79 & $\mathrm{H}$ & 3.46 & 0.81 & $\mathrm{H}$ \\
\hline As a whole & 3.63 & 0.71 & $H$ & 3.55 & 0.76 & $H$ & 3.46 & 0.81 & $H$ & 3.56 & 0.71 & $H$ \\
\hline
\end{tabular}

\section{Difference in the Level of Adaptive Capacities}

The result of the analysis of variance revealed that there was no significant difference in the level of adaptive capacities when grouped by the type of respondents. However, a significant difference was found when respondents were grouped according to location. Post hoc test revealed that the rating of the respondents from Campus $A$ was significantly lower than that of the other respondents, especially on the facilities. The low rating of Campus A can be attributed to its local situation. In terms of population, it caters mostly to the marginalized sector who cannot afford to spend college education in the cities. Its natural resources are limited to small areas, hence, without many agricultural activities. As to the facilities, the completion is still in progress, subsequently contributing to the significantly lower assessments of the respondents compared to the other campuses. This finding corroborates the study of Prantilla and Laureto (2013) that location, among others, may determine the awareness and adaptive capacities in responding to the effects of disasters and climate change.

Moreover, the findings confirm those of Ballaran et al. (2014) that most of the lowlands and coastal areas are significantly affected. With agricultural areas more vulnerable, exposure to climate hazards is imminent. The rating depends on the locality, or that spatial factor is vital in the determination of adaptive capacity. This finding is congruent to that of Cuevas (2012) that geophysical features like the site of the place 
and the natural characteristics such as location, soil quality, and vegetation contributes to the level of adaptive capacity. The conclusion of Ardales et al. (2017) that the interventions for each school must be done independently and that there is no uniform approach to improve the adaptive capacity is found applicable.

\section{Levels of the Vulnerability of the University Campuses}

The vulnerability index of the university campuses as a whole was very low (0.92), which means that the University can handle the impact of the increase in temperature and rainfall. The population has the lowest vulnerability index (0.85) among the three exposed elements and is interpreted as very low. This is attributed to the population's high adaptive capacity and a low to moderate degree of impact. Furthermore, the degree of impact is influenced by the low sensitivity scores due to; lower percentage of dependents, age level within the working-age, an almost equal number of male and female population, less or negligible number of populations with special needs and more secure employment status for the personnel. This result supports the UNDP guide book of Katic (2017), where the effect of the identified indicators leads to an increase or decrease of the social vulnerability of the community. Further supporting this is the study of Murnane, Simpson, and Jongman (2016) that despite having moderate to a high degree of impact score in some system of interest, the vulnerability remained to be low because of the high adaptive capacity.

The overall vulnerability of natural resources $(0.89)$ is very low. Campus $\mathrm{C}$ has the highest score $(\mathrm{VI}=0.99)$ but still very low vulnerability despite having a vast area than the other two campuses, which also have very low ratings. Very low ratings are attributed to the various agricultural projects, and an alternative production process employed.

These findings of low vulnerability of agricultural production is contrary with the findings of the study of Prantilla and Laureto (2013) which revealed that lowland rice farmers are not aware that continuous flooding of rice fields and using of fertilizers can add to global warming and climate change, hence more vulnerable to change in rainfall and increase in temperature.

In terms of critical facilities, the indicators used during the assessment were: construction materials, building condition, structure employing hazard mitigation design, date of construction, government regulations, and access to infrastructurerelated mitigation measures per HLURB guidelines. Additional indicators include alternative sources (water, power), the percentage of classrooms well ventilated, the percentage of classrooms directly exposed to sunlight, percentage of the classrooms with cooling systems, and capacity to handle future climate change impacts as agreed and identified during the group discussions and impact chain analysis.

The overall vulnerability index for critical facilities is the highest among the three $(\mathrm{VI}=0.94)$ but still interpreted as very low. Low vulnerability scores mean that the structure may experience minor damages but may still be effective despite the expected changes in the temperature and rainfall. The relatively higher vulnerability index is caused by the presence of old buildings, incomplete structures, and further aggravated by having classrooms that cater to students beyond the carrying capacity, thereby affecting learning. 
This is most notable in campus $\mathrm{C}$ with most facilities are not yet completed, such as the pavement and the footwalk that require roofing to maximize their use. On the other hand, Campus $\mathrm{C}$ has a moderate overall vulnerability except for the water system identified as being the most vulnerable to an increase in temperature. Finally, Campus B has the "low vulnerability" for most basic infrastructures while "very low vulnerability" in terms of classrooms since these are mostly new and provided with an air-conditioning system.

During the assessment process, it was observed that there were differences in the ratings of the faculty and students. Faculty rated the facilities moderate, while students rated the facilities low. This finding affirms the study of Caelian (2015) that the level of awareness on the vulnerability of respondents largely depends on their appreciation of vulnerability, hence, revealing significant differences. Furthermore, this finding supports the study of Brown et al. (2012) that the situation may be aggravated by local perceptions and interpretation of climate variability, which can be broad and diverse within different social groups and between communities. The study further implies that as the climate continues to change, the current local practices, processes, systems, and infrastructure which have been adapted could become increasingly inappropriate or unsuitable.

Table 2. The Vulnerability of the Campuses and University

\begin{tabular}{|c|c|c|c|c|c|c|c|c|}
\hline \multirow{2}{*}{$\begin{array}{c}\text { System of } \\
\text { Interest }\end{array}$} & \multicolumn{2}{|c|}{ Campus A } & \multicolumn{2}{|c|}{ Campus B } & \multicolumn{2}{|c|}{ Campus C } & \multicolumn{2}{|c|}{ As A Whole } \\
\hline & Mean & Int & Mean & Int & Mean & Int & Mean & Int \\
\hline Population & 0.93 & VL & 0.82 & VL & 0.81 & VL & 0.85 & VL \\
\hline \multicolumn{9}{|c|}{ Critical Facilities } \\
\hline Road & 1.29 & $\mathrm{~L}$ & 0.79 & VL & 0.63 & VL & 0.82 & VL \\
\hline Footwalk & 1.33 & $\mathrm{~L}$ & 0.54 & $\mathrm{VL}$ & 0.57 & $\mathrm{VL}$ & 0.82 & VL \\
\hline Water & 0.76 & VL & 1.03 & $\mathrm{~L}$ & 1.66 & $\mathrm{~L}$ & 1.15 & L \\
\hline Communication & 0.91 & VL & 1.05 & $\mathrm{~L}$ & 0.97 & VL & 0.98 & VL \\
\hline Power & 0.67 & VL & 1.17 & $\mathrm{~L}$ & 1.44 & $\mathrm{~L}$ & 1.1 & L \\
\hline Other Facilities & 0.83 & $\mathrm{VL}$ & 0.73 & $\mathrm{~L}$ & 0.71 & $\mathrm{~L}$ & 0.76 & VL \\
\hline \multicolumn{9}{|c|}{ Natural Resources } \\
\hline Other & 0.83 & VL & 0.71 & $\mathrm{VL}$ & 1.14 & $\mathrm{~L}$ & 0.89 & VL \\
\hline Overall & 0.94 & VL & 0.82 & VL & 0.99 & VL & 0.92 & VL \\
\hline
\end{tabular}

\section{Level of Risk to Flooding and Landslides}

The risk index to flooding and landslides of university campuses range from low, medium to high. Low-risk index means it is less likely to experience a hazard; medium risk level means the campus may have a moderate chance to experience the hazard while the high-risk level means frequent to moderate chance of experiencing the hazard that may significantly affect or damage the Campus. 
The level of risk to flooding and landslides in the three university campuses were determined using community evaluation consistent with the study of Nirupama (2012) that community involvement and participation, especially of experts, are essential factors for a successful disaster mitigation program. Furthermore, the risk indices of the three campuses were computed based on the severity of consequence and the likelihood of occurrence of the specific hazards, as confirmed in the study of Zhou, Liu, Wu, \& Li (2015).

The risk of flooding of Campus A is moderate, while that of Campus B is high. The moderate result for Campus $A$ is attributed to its moderate severity of consequence despite having a moderate occurrence (every 4-10 years) of flooding. On the other hand, the high rating of Campus $B$ is attributed to its high severity of consequence and moderate frequency of occurrence of flood in the area. This finding substantiated the study of Ciurean et al. (2016) that for landslide vulnerability assessment, approaches differ due to different foci and objectives addressed. There is no risk of flooding in Campus $\mathrm{C}$ considering its location of being in the mountainous and highland area of the city.

In the case of a landslide, both Campus B and $C$ have low risk while there is no risk for Campus $A$ because of its location, which is in a relatively flat area. During the assessment in Campus A, historical data was provided. This result finds support in Nirupama (2012) that assessment of risk involves community perception. The findings are also shared by the study of Bruno Soares, Gagnon, and Doherty (2012), having a different approach and method used in the process. The Asian Disaster Preparedness Center used the following criteria: awareness of the landslide risk, landslide mechanism, and vulnerability factors as determined by barangay and DRRM officials, and hazard/ vulnerability risk mapping, among others. Landslide risk mapping combined the analysis of the results of the landslide hazard mapping and the vulnerability factors which highlighted the number of people exposed to possible landslide events, as well as the potential loss of properties in case a specific natural hazard occurs.

Table 3. The Risk Index of University Campuses to Flooding and Landslide

\begin{tabular}{|c|c|c|c|c|c|c|c|c|}
\hline \multirow{3}{*}{ Campus } & \multicolumn{8}{|c|}{ Hazard } \\
\hline & \multicolumn{4}{|c|}{ Flooding } & \multicolumn{4}{|c|}{ Landslide } \\
\hline & SoC & LoO & $\begin{array}{l}\text { Risk } \\
\text { Score }\end{array}$ & $\begin{array}{l}\text { Risk } \\
\text { Index }\end{array}$ & SoC & LoO & $\begin{array}{l}\text { Risk } \\
\text { Score }\end{array}$ & $\begin{array}{c}\text { Risk } \\
\text { Index }\end{array}$ \\
\hline A & 2 & 5 & 10 & Med & \multicolumn{4}{|c|}{ None } \\
\hline B & 3 & 5 & 15 & High & 1 & 4 & 4 & Low \\
\hline C & \multicolumn{4}{|c|}{ None } & 1 & 4 & 1 & Low \\
\hline
\end{tabular}

SoC= Severity of Consequence; LoO $=$ Likelihood of Occurrence

\section{Challenges encountered by University Campuses}

Challenges encountered by campuses were: insufficiency of water supply, lack of awareness, lack of equipment, and facilities such as ambulance and evacuation centers. The continued insufficiency of water and the inadequacy of facilities may later result in the higher vulnerability of these institutions to climate change and disasters. Other challenges include garbage management, which may trigger flooding, maintenance of roads not only within the Campus but including those of the external 
environment or the community, lack of resources, lack of local support, and the influence of the coupled human-environment. These other challenges may result in a higher risk of hazards and contribute to inefficiency in the delivery of services by the university campuses. Further, the adaptive capacities of these institutions may lessen, particularly in the area of population.

These challenges are also cited in the study of Acosta et al. (2016) that human loss and property damage caused psychological distress to affected people undermining the capacity to adapt to the next disasters. The lack of resources was highlighted by the Commission on Audit (COA), who recommended that the government should focus on preparing for, responding to, and recovering from any catastrophic disaster. While Onyango, Sahin, Awiti, Chu, and Mackey (2016) recommended for the adoption of an integrated assessment framework using the Bayesian Belief Network (BBN) at the community level using both quantitative and qualitative methods with stakeholder engagement parallel with what was used in this study.

Most of these challenges were also identified in the study conducted in Zimbabwe which noted that there is uncertainty associated with climatic variability because an important effect of "climate change is that future climate would be less familiar, more uncertain, and possibly more extreme" (Brown et al., 2012). The findings of this study are in harmony with the Sendai Framework for Disaster Risk Reduction 2015-2030, which emphasized all dimensions of disaster risk. Thus, information gathering, periodic pre-disaster assessment, updating and information dissemination, capacity building of government officials and institutions at all levels, and a participatory and people-centered approach to disaster risk prevention has to be prioritized. UNISDR (2015) identified the role of government and research institutions and the different stakeholders, including the academe, to have a more collaborative action and complementary roles in addressing risk prevention.

The finding of the "human coupled environment" as a challenge in this study corroborates Willeges, Mechler, Bowyer, and Balkovic (2017) that linking climate and social science involved different areas. Their study concluded that a better understanding of adaptive capacity and an improved empirical basis for selecting indicators could greatly improve the robustness of the results and highlight key areas to better couple climate change with socio-economic analyses.

Overall findings are indicative of the integration of biophysical and social dimensions of vulnerability that looks into the dynamic, cross-scale interactions of coupled human-environment systems as also disclosed in the study of Matyas and Pelling (2015). Results also show that successful environmental governance depends upon the fit between the institution (University campuses) and the social-ecological system. The findings validated the theory of Ostrom.

Further, although the vulnerability and risk levels of the different exposed elements (population, natural resources, and critical facilities) as a whole were very low, yet without the collaborative action of the external environment (barangay, LGU) the coping mechanism of University campuses, whether short or long term, anticipatory or reactive, may be influenced by the resilience of the coupled system. The risks may be occurring within the system (University campus) or outside the system (barangay or LGU), but due to the interconnectivity and the existing link between the Campus and 
the community, these risks affect and influence the University system. This finding also validated the applicability of the SES theory used in this study.

\subsection{Conclusion}

The exposed elements of university campuses can cope and manage the impact of climate change and disaster at present. However, there is a need for improving their adaptive capacity, especially on facilities which, if not be funded in the next few years, may endanger the safety of its population.

Vulnerability and risk of the different campuses are within tolerable levels but have to be treated differently to address each priority area. Continuous effects of reduced availability of water supply lower agricultural production could lead to loss of livelihoods, internal displacement of the population, and higher food insecurity; thus, the disruption of the University operation. This finding implies that university campuses may not withstand climate change and disasters that are becoming unpredictable.

The risk of flooding is a threat to the population with the possible outbreak of water-borne diseases, placing additional stress on the already inadequate health services, and contributing to the overall deterioration of public health. Continuous flooding on the streets toward the campus, coupled with occasional flooding within the campus, can lead to frequent disruption of classes.

Finally, the challenges outlined by the respondents should be given serious consideration by crafting policies and measures to prevent and mitigate disasters, and climate change and be included in plans and programs of every university campus. The study further implies that as the climate continues to change, the current local practices, processes, systems, and infrastructure of the university could become increasingly inappropriate or unsuitable. Solutions to be made must take into consideration the interconnection and dynamic aspect of the social, ecological, and physical features unique for each campus.

The study is limited by the availability of information on other hazards and the expert with in-depth knowledge of the locality. These must be considered by future researchers in the conduct of further studies related to vulnerability and risk assessment to improve the result of the assessment.

\section{REFERENCES}

Abdul-Razak, M., \& Kruse, S. (2017). The adaptive capacity of smallholder farmers to climate change in the Northern Region of Ghana. Climate Risk Management, 17, 104-122. doi: 10.1016/j.crm.2017.06.001

Acosta, L. A., Eugenio, E. A., Macandog, P. B. M., Macandog, D. B. M., Lin, E. K. H., Abucay, E. R., Primavera, M. G. (2016). Loss and damage from typhoon-induced floods and landslides in the Philippines: community perceptions on climate impacts and adaptation options. International Journal of Global Warming, 9(1), 33. doi: 10.1504/ijgw.2016.074307

Alcayna, T., Bollettino, V., Dy, P., \& Vinck, P. (2016). Resilience and disaster trends in the Philippines: opportunities for national and local capacity building. PLoS currents, 8 
Ardales G.Y. Jr., Espaldon, M.V.O, Lasco, R.D., Quimbo, M.A.T., Zamora, O.B. (2017). Adaptive Capacity Index of Public Schools in the Municipalities of Bay and Los Baños, Laguna. Philippines. Journal of Environmental Science and Management 20-1

Ballaran, V. G., Mendoza, M., Bayani-Arias, J., Dorado, R., \& Burgos. B., (2014). Climate Change Vulnerability Mapping of Selected Municipalities in Laguna, Philippines. Southeast Asian Regional Center for Graduate Study and Research in Agriculture.

Brown, D., Chanakira, R. R., Chatiza, K., Dhliwayo, M., Dodman, D., Masiiwa, M., ... \& Zvigadza, S. (2012). Climate change impacts, vulnerability, and adaptation in Zimbabwe (pp. 1-40). London, UK: International Institute for Environment and Development.

Bruno Soares, M., S. Gagnon, A., \& M. Doherty, R. (2012). Conceptual elements of climate change vulnerability assessments: a review. International Journal of Climate Change Strategies and Management, 4(1), 6-35.

Caelian, Z. (2015). Disaster resiliency in the third district of Negros Occidental. (Unpublished Doctoral dissertation). University of Negros Occidental-Recoletos, Bacolod City.

Ciurean, R. L., Schröter, D., \& Glade, T. (2013). Conceptual frameworks of vulnerability assessments for natural disasters reduction. In Approaches to disaster management-Examining the implications of hazards, emergencies, and disasters. IntechOpen.

Cuevas, S. (2012). Examining climate change adaptation measures: an early warning system in the Philippines. International Journal of Climate Change Strategies and Management, 4(4), 358-385.

Cumming, G. S. (2014). Theoretical frameworks for the analysis of social-ecological systems. In Social-Ecological Systems in Transition (pp. 3-24). Springer, Tokyo.

Eckstein, D., Künzel, V., and Schäfer, L. (2018). Global Climate Risk Index 2018. Bonn, Germany. Germanwatch. Retrieved from https://germanwatch.org/sites/germanwatch.org/files/ publication/ 20432. Pdf

Epstein, G., Sandberg, A., Bay-Larsen, I., \& Hovelsrud, G. (2014). Institutions and adaptation processes: A social-ecological system approach for the study of adaptation to climate change. Prepare for submission to the Journal of Institutional Economics.

Fakhruddin, S. H. M., Babel, M. S., \& Kawasaki, A. (2015). Assessing the vulnerability of infrastructure to climate change on the Islands of Samoa. Natural Hazards and Earth System Sciences, 15(6), 1343-1356.

Gomez, N. (2015). Climate change and adaptation on selected crops in Southern Philippines. International Journal of Climate Change Strategies and Management, 7(3), 290-305.

Good, C. V., \& Scates, D. E. (1954). Methods of research. Appleton-Century-Crofts. 
Institute for International Law of Peace and Armed Conflict. (2018). The World Risk Report, 2018. Bündnis Entwicklung Hilft and Ruhr University Bochum. Retrieved from https:// weltrisikobericht.de/english-2/

IPCC, 2012: Managing the Risks of Extreme Events and Disasters to Advance Climate Change Adaptation. A Special Report of Working Groups I and II of the Intergovernmental Panel on Climate Change [Field, C.B., V. Barros, T.F. Stocker, D. Qin, D.J. Dokken, K.L. Ebi, M.D. Mastrandrea, K.J. Mach, G.-K. Plattner, S.K. Allen, M. Tignor, and P.M. Midgley (eds.)]. Cambridge University Press, Cambridge, UK, and New York, NY, USA, 582 pp.

Katic, K. (2017). Social vulnerability assessment tools for climate change and DRR programming [A guide to practitioners]. United Nations Development Programme.

Mabag, P.V. (2015). The disaster preparedness program of the Municipality of Binalbagan. (Unpublished master's thesis). University of Negros Occidental-Recoletos, Bacolod City.

Matyas, D. \& Pelling, M. (2015). Disaster Vulnerability and Resilience: Theory, Modelling, and Prospective. https://doi.org/10.13140/RG.2.1.4684.2409

Murnane, R., Simpson, A., \& Jongman, B. (2016). Understanding risk: what makes a risk assessment successful? International Journal of Disaster Resilience in the Built Environment, 7(2), 186-200.

Nirupama, N. (2012). Risk and vulnerability assessment: A comprehensive approach. International Journal of Disaster Resilience in the Built Environment, 3(2), 103-114.

Onyango, E. A., Sahin, O., Awiti, A., Chu, C., \& Mackey, B. (2016). An integrated risk and vulnerability assessment framework for climate change and malaria transmission in East Africa. Malaria Journal, 15(1), 551.

Ostrom, E. (2009) A General Framework for Analyzing Sustainability of Social-Ecological Systems. Science 325, 419-422

Papa, E.M. (2019). Awareness and implementation of disaster risk reduction management in private higher education institutions. (Unpublished Doctoral dissertation). University of Negros Occidental - Recoletos, Bacolod City.

Prantilla, J. N. D., \& Laureto, A. S. (2013). Adaptation to climate change of lowland rice farmers in Bukidnon, Philippines: A micro-level analysis. Philippines Agricultural Economics and Development Association (PAEDA) 2013 Biennial Convention.

Reams, M. A., Lam, N. S., Cale, T. M., \& Hinton, C. M. (2013). Applying a community resilience framework to examine household emergency planning and exposure-reducing behavior among residents of Louisiana's industrial corridor. Journal of emergency management (Weston, Mass.), 11(2), 107.

Ritchie, J., Lewis, J., Nicholls, C. M., \& Ormston, R. (Eds.). (2013). Qualitative research practice: A guide for social science students and researchers. Sage. 
Spata, A. (2003). Research methods: Science and diversity. John Wiley \& Sons, Incorporated.

Turner, B. L., Roger E. Kasperson, Pamela A. Matson, James J. McCarthy, Robert W. Corell, Lindsey Christensen, Noelle Eckley, Jeanne X. Kasperson, Amy Luers, Marybeth L. Martello, Colin Polsky, Alexander Pulsipher, and Andrew Schiller. (2003). A framework for vulnerability analysis in sustainability science. Proceedings of the National Academy of Sciences 100 (14): 8074-8079.

Wamsler, C., E. Brink, and O. Rantala. 2012. Climate change, adaptation, and formal education: the role of schooling for increasing societies' adaptive capacities in El Salvador and Bazil. Ecology and Society 17(2): 2

UN/ISDR (United Nations - International Strategy for Disaster Reduction). (2015). Sendai Framework for disaster risk reduction 2015-2030, the outcome of the third world conference on disaster risk reduction [A/CONF.224/ CRP.1], 14-18 March 2015, Sendai, Japan

Zhou, Y., Liu, Y., Wu, W., \& Li, N. (2015). Integrated risk assessment of multi-hazards in China. Natural Hazards, 78(1), 257-280. 